\title{
EDITORIAL
}

\section{The microbiologist as a contact lens wearer}

\section{Contact lens-associated keratitis}

Approximately 1.3 million persons in the UK wear contact lenses $(\mathrm{CL})^{1}$ and a proportion develop microbial keratitis as a direct consequence of their use. The likelihood of succumbing to CL-associated microbial keratitis is dependent, at least in part, on the type of CL. The relative risk for, and incidence of, microbial keratitis associated with the different $\mathrm{CL}$ types is shown in the table; generally, soft CL carry a greater risk than hard CL. Of soft CL, extended-wear (overnight) and "disposable" types carry a greater risk of keratitis than daily-wear soft CL.

Table. Relative risk for, and incidence of, microbial keratitis associated with different types of contact lens

\begin{tabular}{|c|c|c|c|c|}
\hline \multirow{2}{*}{ Type of lens } & \multicolumn{3}{|c|}{ Relative risk* } & \multirow{2}{*}{$\begin{array}{c}\text { Incidence } \dagger \\
(/ 10000)\end{array}$} \\
\hline & I & II & III & \\
\hline \multicolumn{5}{|l|}{ Hard $(40 \%) \ddagger$} \\
\hline $\begin{array}{l}\text { gas permeable } \\
\text { rigid }\end{array}$ & $1.0 \$$ & $1 \cdot 0$ & $1 \cdot 3$ & $4 \cdot 0$ \\
\hline $\begin{array}{l}\text { polymethyl- } \\
\text { methacrylate rigid }\end{array}$ & $1 \cdot 3$ & 0.5 & - & $2 \cdot 0$ \\
\hline \multicolumn{5}{|l|}{ Soft $(60 \%)+$} \\
\hline daily-wear & $3 \cdot 6$ & $1 \cdot 0 \S$ & $1.0 \S$ & $4 \cdot 1$ \\
\hline extended-wear & $20 \cdot 8$ & $5 \cdot 15$ & $6 \cdot 3$ & $20 \cdot 9$ \\
\hline "disposable" & - & - & $19 \cdot 4$ & - \\
\hline \multicolumn{5}{|c|}{$\begin{array}{l}\text { * Data from Dart et al. } .^{2}(\mathrm{I}) \text {, Poggio et al. }{ }^{3}(\mathrm{II}) \text {, Buehler et al. }{ }^{4} \text { (III) } \\
\dagger \text { Data from Poggio et al. } .^{3} \\
\ddagger \text { Percentage prescribed by optometrists. } \\
\S \text { Referent value. }\end{array}$} \\
\hline
\end{tabular}

Pseudomonas aeruginosa is the most important cause of acute necrotising keratitis for the CL wearer. ${ }^{5}$ Infection is due primarily to the inability of the avascular cornea to mount an acute inflammatory reaction. $P$. aeruginosa can multiply on the $C L$ to form a biofilm which is protected from the antimicrobial action of tears. In a rabbit model, it has been demonstrated that if a breach occurs in the corneal epithelium and a sufficient number of viable bacteria are planktonic in the tear film, adhesion to the cornea can occur in about $15 \mathrm{~min}$; complete penetration of the corneal epithelium occurs after $1 \mathrm{~h} .^{6}$ The progress of infection is rapid and within $72 \mathrm{~h}$ acute endophthalmitis may develop, a condition which may require evisceration.

About 1 in $250000 \mathrm{CL}$ wearers develop keratitis as a result of corneal infection with Acanthamoeba. ${ }^{7}$ This protozoan is ubiquitous in soil and aquatic environments, including domestic tap water, ${ }^{8}$ and human exposure to Acanthamoeba, assessed by the presence of specific antibody, appears to be common. ${ }^{9}$ Acanth- amoeba infection of the eye is commonly associated with daily-wear of soft CL (including "disposable" $\mathrm{CL}^{10}$ ), but can also occur with other types of CL. ${ }^{7}$ Unlike other organisms, Acanthamoeba appears to initiate infection of the cornea by direct invasion of the epithelium, ${ }^{11,12}$ although epithelial disruption by hypoxia or mechanical trauma may be involved. Corneal infection with Acanthamoeba is particularly painful, and is difficult to treat by chemotherapy.

Attempts have been made to reduce the risk of CLassociated microbial keratitis by introducing a 14-daywear "disposable" lens. This is a misleading term since the "disposable" lens has to be cleaned and disinfected daily in a re-usable storage case, a procedure which predisposes it to microbial contamination; gram-negative bacteria and Acanthamoeba have been isolated from storage cases. ${ }^{13-15}$ This contamination rate is c. $45 \%$ for bacteria and $7 \%$ for Acanthamoeba, indicating that disinfection by the CL user is often unsatisfactory. There is strong circumstantial evidence to connect these storage cases with subsequent microbial keratitis, although $P$. aeruginosa can cause keratitis with extended-wear CL in the absence of storage-case contamination (F. Stapleton, personal communication). There are considerable differences in the efficacy of CL-disinfecting solutions against organisms which have the potential to induce microbial keratitis; ${ }^{16}$ e.g. chlorine-based systems are ineffective against Acanthamoeba cysts. $^{17}$

\section{The microbiologist and contact lenses}

Should microbiologists who wear CL be concerned about developing microbial keratitis as a consequence of their work? There are no published epidemiological data identifying CL-wearing microbiology laboratory personnel as being at greater risk than other $C L$ users of acquiring microbial keratitis as a direct consequence of their work. Nevertheless, the microbiology laboratory provides an environment with increased risk of exposure to organisms with the potential to cause keratitis. Organisms, including viruses, bacteria, fungi and protozoa, ${ }^{18}$ may gain access to the ocular surface either as a consequence of laboratory accidents, such as splashing or aerosolisation of cultures, or via direct transfer from contaminated fingers or microscope eyepieces to the eyelid margin or CL. However, CL are not sterile; they are contaminated with normal eyelid flora and may, as already outlined above, become contaminated with gram-negative bacteria and amoebae from ineffective disinfection in re-usable storage cases. There is thus a balance of risk between such "normal" contamination and acquisition of 
other organisms likely to cause keratitis due to exposure in the laboratory. In view of the latter, extended-wear CL are not recommended for staff working in microbiology laboratories and, at present, it would be prudent to avoid the 14-day-wear "disposable" CL until the increased incidence of keratitis associated with their use is better understood.

CL-wearers should avoid touching their eyelids or CL while handling bacterial (especially $P$. aeruginosa) culture plates, particularly if extended-wear CL are worn. To prevent this route of contamination, goggles could be worn. They should always be worn for handling cultures of Acanthamoeba or for handling liquid cultures of organisms, especially in large volumes, when aerosolisation is likely to occur. Handling large-volume cultures in exhaust-protective cabinets is regarded as good laboratory practice and is strongly recommended to the CL-wearing microbiologist.

Microbiologists must take additional care of their CL. This involves daily washing of storage cases with boiled water $\left(>70^{\circ} \mathrm{C}\right)$ and storing them dry to prevent multiplication of gram-negative rods and amoebae..$^{8,16}$ CL should ideally be disinfected by heat (pasteurisation) or by immersion in hydrogen peroxide for $2 \mathrm{~h}$ in clean "near-sterile" cases. ${ }^{16}$ If such care is taken, microbiologists should be at no greater risk of CLassociated keratitis than other $\mathrm{CL}$ wearers. If eyes are contaminated with organisms as a consequence of a laboratory accident, the CL should be removed im- mediately and a disposable, sterile eyewash solution (e.g., isotonic saline) should be applied liberally to dilute the inoculum and minimise the chance of infection, as in all such accidents.

An additional concern to both microbiologists and other laboratory staff is contamination of eyewash solutions by Acanthamoeba. ${ }^{19,20}$ Such contamination could result in amoebic keratitis following accidental injury to the cornea. ${ }^{21}$ Eyewash solutions, and indeed tap water, often depend upon chlorine-based agents for antimicrobial action and the concentration of active chlorine present is ineffective against Acanthamoeba cysts. ${ }^{22}$ Hence, sterile single-use sachets should be used.

For all CL wearers, fastidious lens hygiene and strict attention to disinfecting regimens are the most important aspects of prophylaxis against microbial keratitis. However, this is not current practice, especially amongst younger persons whose compliance remains unsatisfactory. ${ }^{23} \mathrm{CL}$ have clear advantages over conventional spectacles in the performance of many microbiological procedures, especially microscopy. Nevertheless, CL wearers in microbiology laboratories should be aware that their CL require the same level of attention that they give to other aspects of personal safety in the laboratory.

D. V. SEAL and J. HAY

Glasgow Royal Infirmary, Bacteriology Laboratory, Wolfson Centre, 31 Taylor Street, Glasgow G4 0NA.

\section{References}

1. Pearson RM. Contact lens trends in the UK in 1991. $\mathrm{J} \mathrm{Br}$ Contact Lens Assoc 1992; 15: 17-23.

2. Dart JKG, Stapleton F, Minassian D. Contact lenses and other risk factors in microbial keratitis. Lancet 1991; 338: $650-653$

3. Poggio EC, Glynn RJ, Schein OD et al. The incidence of ulcerative keratitis among users of daily-wear and extended-wear soft contact lenses. $N$ Engl J Med 1989; 321: 779-783.

4. Buehler PO, Schein OD, Stamler JF, Verdier DV. The increased risk of ulcerative keratitis among disposable soft contact lens users. Investig Ophthalmol and Visual Science 1992; 33 Suppl: S1209.

5. Dart JKG, Seal DV. Pathogenesis and therapy of Pseudomonas aeruginosa keratitis. Eye $1988 ; 2$ : S46-55.

6. Stern GA, Labniewski A, Allen C. The interaction between Pseudomonas aeruginosa and the corneal epithelium: an electron microscope study. Arch Ophthalmol 1985; 103: 1221-1225.

7. Stehr-Green JK, Bailey TM, Visvesvara GS. The epidemiology of Acanthamoeba keratitis in the United States. Am J Ophthalmol 1989; 107: 331-336.

8. Seal DV, Stapleton F, Dart J. Possible environmental sources of Acanthamoeba spp. in contact lens wearers. $B r J$ Ophthalmol 1992; 76: 424-427.

9. Cursons RTM, Brown TJ, Keys EA. Immunity to pathogenic free-living amoebae (letter). Lancet 1977; 2: 875-876.

10. Heidemann DG, Verdier DD, Dunn SP, Stamler JF. Acanthamoeba keratitis associated with disposable contact lenses. Am J Ophthalmol 1989; 110: 630-634

11. Campbell J, Mehta R, Robinson D, Osato M. The pathogenesis of experimental Acanthamoeba keratitis. A morphologic study by scanning electron microscopy. Invest Ophthalmol Vis Sci 1989; 30 Suppl : 40.

12. Osato M, Pyron M, Elizondo M, Brown E, Wilhemus $\mathrm{K}$. Adherence and penetration of human corneal epithelium by Acanthamoeba. Invest Opthalmol Vis Sci 1990; 31 Suppl: 420.

13. Donzis PB, Mondino BJ, Weissman BA, Bruckner BA. Microbial contamination of contact lens care systems. $A m J$ Ophthalmol 1987; 104: 325-333.

14. Larkin DFP, Kilvington S, Easty DL. Contamination of contact lens storage cases by Acanthamoeba and bacteria. Br J Ophthalmol 1990; 74: 133-135.

15. Devonshire P, Munro FA, Abernethy C, Clark BJ. Microbial contamination of contact lens cases in the West of Scotland. Br J Ophthalmol 1992; $71: 41-45$.

16. Seal DV, Hay J. Contact lens disinfection and Acanthamoeba: problems and practicalities. Pharm J 1992; 248: 717-719.

17. Seal DV, Hay J, Devonshire P, Kirkness CM. Acanthamoeba and contact lens disinfection: should chlorine be discontinued? Br J Ophthalmol 1992; 77: 128.

18. Smolin G, Friedlaender MH. Eds. Contact lenses. Int Ophthalmol Clin 1991 ; 31 Suppl 2: 1-188p.

19. Tyndall RL, Lyle MM, Ironside KS. The presence of free-living amoebae in portable and stationary eye wash stations. $\mathrm{Am}$ Ind Hyg Assoc J 1987; 48: 933-934.

20. Paszko-Kolva C, Yamamoto $H$, Shahamat M, Sawyer TK, Morris G, Colwell RR. Isolation of amoebae and Pseudomonas and Legionella spp. from eyewash stations. Appl Environ Microbiol 1991; 57: 163-167.

21. Sharma S, Srinivasan M, George C. Acanthamoeba keratitis in non-contact lens wearers. Arch Ophthalmol 1990; 108: 676-678.

22. Kilvington S, Price J. Survival of Legionella pneumophila within cysts of Acanthamoeba polyphaga following chlorine exposure. J Appl Bacteriol 1990; 68: 519-525.

23. Sokol JL, Mier MG, Bloom S, Asbell PA. A study of patient compliance in a contact lens wearing population. Contact Lens Assoc Ophthalmol J 1990; 16: 209-213. 